\title{
A study of association between self feeding practices and nutritional status of infants in a rural population
}

\author{
Sreedhara MS ${ }^{1}$, Sudarshan K. $\mathbf{P}^{2}$, Kruthika $\mathbf{K}^{3}$ \\ ${ }^{1}$ Dr Sreedhara M. S, Assistant Professor, Department of Pediatrics, Sri Siddhartha Medical College, Tumkur, Karnataka, \\ India, ${ }^{2}$ Dr Sudarshan K. P, Associate Professor, Department of Paediatrics. Sreedevi Medical College, Tumkur, \\ Karnataka, India, ${ }^{3}$ Dr Kruthika K, Post Graduate, Department of Community Medicine, JNMC, Belagavi, Karnataka, \\ India.
}

Address for Correspondence: Dr. Sreedhara M. S., Assistant Professor, Department of Paediatrics, Sri Siddhartha Medical College, Tumkur, Karnataka, India. Email id: drsreedharms@gmail.com

\begin{abstract}
Background: Feeding practices determine the nutritional status of infants. Infant and young child feeding practices include appropriate breastfeeding and complementary feeding practices. The impact of complementary feeding in the form of proper timing, quantity and quality of food on nutritional status is a matter of study in many research works. But nutritional status not only depends on type and amount of food but also on how it's fed. Responsive feeding which includes encouraging the child to feed him or her also improves nutritional status. Objective: To assess the impact of self-feeding practice on nutritional status of children. Materials and Methods: A cross sectional study was done between December 2015 to January 2016 on 200 infants between 9 months to 1 year in field practice area of Sri Siddhartha Medical College Tumkur. Results: Of the 200 infants who were studied, self feeding was initiated early ( 8 to 10 months) in 158 infants and late (after 10 months) in 42 . The prevalence of stunting was significantly less in early selffeeding group (18.98\%) compared to late self-feeding group (47.14\%) with P value of $<0.001$. The prevalence of wasting was also found to be significantly less in early self-feeding group (37.9\%) compared to late self-feeding group (66.66\%) with $\mathrm{P}$ value of $<0.001$. Conclusion: There is a significant association between early self-feeding practices and better nutritional status of infants.
\end{abstract}

Key words: Self-feeding, Nutritional status, Complementary feeding.

\section{Introduction}

It has long been recognized that the period from birth to two years of age is a "critical window" for the promotion of optimal growth, health and behavioural development. Infant-feeding practices constitute a major component of child caring practices apart from socio-cultural, economic and demographic factors [1]. Appropriate feeding practices play a crucial role in achieving optimal health outcomes in infancy as well as in later life. In addition to inadequate quantities and diversity of food, nutritionists increasingly recognize an unresponsive feeding style as a crucial impediment to healthy nutrition [2]. Poor infant-feeding practices can lead to stunted growth, delayed motor and mental development, immune incompetence, and increased risk

Manuscript received: $4^{\text {th }}$ June 2016

Reviewed: $13^{\text {th }}$ June 2016

Author Corrected; $24^{\text {th }}$ June 2016

Accepted for Publication: $9^{\text {th }}$ July 2016 of infectious diseases such as diarrhoea [3, 4]. Guidelines for infant-feeding practices in developing countries to date have focused primarily on their relationship to child malnutrition $[5,6]$. Self feeding, whereby the mother feeds her child in response to child cues and psychomotor abilities, is low in some countries and likely contributes to malnutrition [2]. The child's food preferences and practices are initiated very early in life. Educational interventions for families of young children may have immediate nutritional benefit as well as helping to reduce both infectious and chronic disease risks when learned healthful habits and preferences are carried into adulthood [7, 8-12].

Thus, appropriate management of malnutrition in early childhood can prevent short-and long-term consequences. Hence the present study was conducted 
with the objective to assess the impact of appropriate self-feeding practice on nutritional status of children.

\section{Materials and Methods}

A prospective cross sectional study was done between December 2015 to January 2016 on 200 infants between 9 months to 1 year in field practice area of Sri Siddhartha Medical College Tumkur. Infants with Low birth weight $(<2.5 \mathrm{~kg})$, multiple gestations, Prematurity, Children with significant congenital malformations and infants with chronic illness were excluded from the study. Data on feeding practices was collected by interviewing mothers on a pre-tested semi-structured schedule after due consent. These children were examined and their nutritional status was assessed by anthropometry. The children were divided in to two groups based on when self feeding was initiated, a) early self feeding group (self feeding initiated between 8 to 10 months), b) late self feeding group (self feeding initiated after 10 months). Weight and length of the children at 1 year was plotted on WHO growth charts (2006). Prevalence of wasting (weight for length below $3^{\text {rd }}$ percentile) and stunting (length for age below $3^{\text {rd }}$ percentile) were calculated for early and late self feeding groups. The relationship between self feeding practice and nutritional status was analyzed.

\section{Results}

In the present study, $57 \%$ of the infants were male and $43 \%$ were female. Among them $80 \%$ of the children lived in nuclear families and $20 \%$ in joint families. $27 \%$ of children were born first order, $37 \%$ second order, $24 \%$ third, $10 \%$ fourth and $2 \%$ fifth order. None of the children were of the birth order of more than 6 .

Majority ( $88 \%$ ) of the study infants were born in hospital and $12 \%$ were born in home among those $10 \%$ were conducted by trained dais and $2 \%$ by untrained dais. Initiation of self feeding practices in our study showed that majority $(79 \%, n=158)$ of the infants started their self feeding between the age of $8-10$ months and only $21 \%(n=42)$ of them started self feeding after 10 months of age [Table:2].

Table-1: General characteristics of the study infants

\begin{tabular}{|c|c|c|}
\hline Characteristics & Number & Percentage \\
\hline Sex: & 114 & $57 \%$ \\
Male & 86 & $43 \%$ \\
Female & 160 & $80 \%$ \\
\hline Family type: & 40 & $20 \%$ \\
Nuclear & & \\
Joint & 54 & $27 \%$ \\
\hline Birth order: & 74 & $37 \%$ \\
One & 48 & $24 \%$ \\
Two & 20 & $10 \%$ \\
Three & 4 & $2 \%$ \\
Four & 0 & 0 \\
Five & & $2 \%$ \\
6 and above & 4 & $10 \%$ \\
\hline Place of birth: & 20 & $88 \%$ \\
\hline Home,untrained dhai & 176 & \\
Home trained dhai & & \\
Hospital & & \\
\hline
\end{tabular}

Table-2: Association between initiation of self feeding practices and stunting and wasting

\begin{tabular}{|c|c|c|c|c|c|}
\hline $\begin{array}{c}\text { Time of initiation of } \\
\text { self feeding }\end{array}$ & $\begin{array}{c}\text { Total } \\
\text { Number }\end{array}$ & Stunting & $\begin{array}{c}\text { No stunting } \\
\mathbf{P}<\mathbf{0 . 0 0 1}\end{array}$ & Wasting & $\begin{array}{c}\text { No wasting } \mathbf{P}< \\
\mathbf{0 . 0 0 1}\end{array}$ \\
\hline $8-10$ months & $158(79 \%)$ & $30(18.98 \%)$ & $128(81.01 \%)$ & $60(37.97 \%)$ & $98(62.03 \%)$ \\
\hline$>10$ months & $42(21 \%)$ & $24(57.14 \%)$ & $18(42.85 \%)$ & $28(66.6 \%)$ & $14(33.3 \%)$ \\
\hline
\end{tabular}


In our study we found a significant association between early initiation of self-feeding practices and better nutritional status (lesser prevalence of wasting and stunting) by chi-square test.

$18.98 \%$ of infants in whom self feeding was initiated early (i-e between $8 ; 10$ months) had stunting, where as $47.14 \%$ infants in whom self feeding was initiated late (after 10 months) had stunting [Table:2].

Our study also showed significant association between initiation of self-feeding practices and wasting among infants. $37.9 \%$ of infants in whom self feeding was initiated early (i-e between $8 ; 10$ months) had wasting, where as $66.66 \%$ infants in whom self feeding was initiated late (after 10 months) had stunting [Table:2].

\section{Discussion}

In the present study, $57 \%$ of the children studied were Male and $43 \%$ were Female. In a study done by Dinesh Kumar et al, $63 \%$ of children were male and $36 \%$ of the study population were female which is similar in comparison with this study [1].

In the present study $80 \%$ were born in hospital. According to NFHS 3 data, 38 to $40 \%$ of total deliveries in our country take place in a health care facility. In a study conducted in rural Karnataka, the deliveries outside a health care facility contributed to 65 $\%$ of the deliveries [13]. In a study conducted in urban slums of Mumbai, Das $\mathrm{S}$ et al found the incidence of hospital deliveries to be $84 \%$, which is the same as in our study [14].

In the present study proportion of stunting was $27 \%$ which was less compared to $66.1 \%$ reported in an earlier survey in Allahabad [17] and also 37.4\% from another study done in Allahabad [1]. The proportion of the infants who showed wasting in our study was $44 \%$ which is quite on higher side compared to other studies $10.6 \%$ and $11.7 \%[1,17]$.

It was observed in a study that poor care was associated with significantly higher Prevalence of stunted and underweight children whereas it did not influence prevalence of wasting amongst children from a study done in Accra [18].

There are not many studies done to evaluate the impact of appropriate self feeding practices and nutritional staus of children. The present study shows that early initiation of self feeding practices helps to enhance the nutritional status of the infants.

\section{Conclusion}

Improvement in child care and feeding practices could positively impact nutritional status of children which can be done by adequate health education to the mothers. It may also be necessary to invest in community level change agents to facilitate the process especially in an already overburdened health system. This study highlights the need to strengthen the ongoing community oriented health education programs, utilize the missed opportunities for improving complementary feeding and self feeding practices by education and imparting information in the urban slum population.

\section{Funding: Nil, Conflict of interest: Nil Permission from IRB: Yes}

\section{References}

1. Kumar D, Goel NK, Mittal PC, Misra P. Influence of infant-feeding practices on nutritional status of underfive children. Indian J Pediatr. 2006 May;73(5):417-21.

2. Aboud FE, Shafique S,Akhter S. A Responsive Feeding Intervention Increases Children's Self-Feeding and Maternal Responsiveness but Not Weight Gain. Journal of Nutrition.2009; 139: 1738-1743.

3. Hediger ML, Overpeck MD, Ruan WJ, Troendle JF. Early infant feeding and growth status of US-born infants and children aged 4-71 mo: analyses from the third National Health and Nutrition Examination Survey, 1988-1994. Am J Clin Nutr. 2000 Jul;72(1): 159-67.

4. Fawzi WW, Herrera MG, Nestel P, el Amin A, Mohamed KA. A longitudinal study of prolonged breastfeeding in relation to child undernutrition. Int $\mathrm{J}$ Epidemiol. 1998 Apr;27(2):255-60.

5. PAHO, 37th Session of the Subcommittee on Planning and Programming of the Excecutive Committee, 2003.

6. PAHO, ProPAN: Process for the Promotion of Child Feeding, 2003. 
7. Birch LL, Fisher JO. Development of eating behaviors among children and adolescents. Pediatrics. 1998 Mar;101(3 Pt 2):539-49.

8. Bentley M, Gavin L, Black MM, Teti L. Infant feeding practices of low-income, African-American, adolescent mothers: an ecological, multigenerational perspective. Soc Sci Med. 1999 Oct;49(8):1085-100.

9. Barton SJ. Infant feeding practices of low-income rural mothers. MCN Am J Matern Child Nurs. 2001 Mar-Apr;26(2):93-7.

10. Fisher JO, Birch LL, Smiciklas-Wright H, Picciano MF. Breast-feeding through the first year predicts maternal control in feeding and subsequent toddler energy intakes.J Am Diet Assoc. 2000Jun;100(6):641-6.

11. Francis LA, Hofer SM, Birch LL. Predictors of maternal child-feeding style: maternal and child characteristics. Appetite. 2001 Dec;37(3):231-43.

12. Kannan S, Carruth BR, Skinner J. Infant feeding practices of Anglo American and Asian Indian American mothers. J Am Coll Nutr. 1999 Jun;18 (3):279-86.

13. Kesterton AJ, Cleland J. Neonatal care in rural Karnataka: healthy and harmful practices, the potential for change. BMC Pregnancy Childbirth. 2009 May 20;9:20. doi: 10.1186/1471-2393-9-20.

14. Das S, Bapat U, More NS, Chordhekar L, Joshi W, Osrin D. Prospective study of determinants and costs of home births in Mumbai slums. BMC Pregnancy Childbirth. 2010 Jul 30;10:38. doi: 10.1186/1471-239310-38.

15. PAHO / WHO. Guiding principles for complementary feeding of the breastfed child. Washington, DC / Geneva, Switzerland: PAHO / WHO, 2004.

16. International Institute for Population Sciences (IIPS) and Macro International. 2007. National Family Health Survey (NFHS-3), 2005-06: India: Volume I. Mumbai: IIPS.

17. Gupta SB, Srivastava BC, Bhushan V and Sharma P. Impact of guidelines on breastfeeding appropriate for India, National the ICDS in UP. Indian Journal of Medical Research 1984; $79: 615$.

18. Ruel M, Levin CE, Armar-Klemusu M, Maxwell DG, Morris SS. Good care practices mitigate the negative effects of poverty and low maternal schooling on children's nutritional status: evidence from Accara. World development report 1999; 27 : 1993-2009.

\section{How to cite this article?}

Sreedhara M.S, Sudarshan K. P, Kruthika K. A study of association between self feeding practices and nutritional status of infants in a rural population. Int J PediatrRes.2016;3(7):509-512.doi:10.17511/ijpr.2016.i07.08. 